\title{
Penerapan Manajemen Kualitas Terhadap Kinerja Mandor Pada Proyek Apartemen
}

\author{
Moch. Muzaki ${ }^{1 *}$, Felicia T. Nuciferani. ${ }^{2}$ \\ ${ }^{1,2}$ Institut Teknologi Adhi Tama Surabaya \\ Program Studi Teknik Sipil, FTSP \\ Email: ${ }^{1}$ zakimuz.zm@gmail.com, ${ }^{2}$ felicia@itats.ac.id \\ Received 22 April 2020; Reviewed 12 Mei 2020; Accepted 29 Mei 2020 \\ Journal Homepage: http://jurnal.borneo.ac.id/index.php/borneoengineering \\ DOI: https://doi.org/10.35334/be.v4i1.1383
}

\begin{abstract}
The Embodiment of construction quality can be achieved by implementing quality management, one of the workforce used in implementing quality management is the foreman. A construction company has standards or guidelines for implementing quality management that must be carried out by the foreman. This study will discuss the relationship between the level of the foreman's ability and the influence of the foreman's ability on the application of quality management. Qualitative descriptive method is done by distributing questionnaires followed by validity, reliability, $t$-test, F-test and classical assumption test. The results showed a simultaneous test for educational variables, work experience, motivation and discipline influenced the ability of the foreman in implementing quality management of 2,510. Partial test shows that the work experience variable influences the foreman's ability to implement quality management by 2,178. So that the test results obtained for the regression model that is $Y=36,130+1,353 X 2+e i$, that work experience has a very dominant influence on the ability of the foreman in implementing quality management in Surabaya apartment building construction projects.
\end{abstract}

Keywords: Overseer ability, Quality management, Work experience

\begin{abstract}
Abstrak
Perwujudan kualitas konstruksi dapat dicapai dengan penerapan manajemen kualitas, salah satu tenaga kerja yang digunakan dalam penerapan manajemen kualitas adalah mandor. Suatu perusahaan konstruksi memiliki standar atau pedoman baku guna penerapan manajemen kualitas yang wajib dijalankan oleh mandor. Penelitian akan membahas tentang hubungan tingkat kemampuan mandor beserta pengaruh kemampuan mandor pada penerapan manajemen kualitas. Metode deskriptif kuantitatif dilakukan dengan cara penyebaran kuesioner diikuti uji validitas, reliabilitas, uji $t$, uji $F$ dan uji asumsi klasik. Hasil penelitian menunjukkan uji simultan untuk variabel pendidikan, pengalaman kerja, motivasi dan disiplin berpengaruh terhadap kemampuan mandor dalam menerapkan manajemen kualitas sebesar 2,510. Uji parsial menunjukkan bahwa variabel pengalaman kerja berpengaruh terhadap kemampuan mandor dalam menerapkan manajemen kualitas sebesar 2,178. Sehingga didapatkan hasil pengujian untuk model regresi yaitu $Y=36,130+1,353 X 2+e i$, bahwa pengalaman kerja berpengaruh sangat dominan terhadap kemampuan mandor dalam penerapan manajemen kualitas pada proyek pembangunan gedung apartemen Surabaya.
\end{abstract}

Kata kunci : Kemampuan mandor, Manajemen kualitas, Pengalaman kerja. 


\section{Pendahuluan}

Manajemen kualitas atau Project Quality Management merupakan proses suatu proyek terkait pemenuhan kebutuhan yang disetujui, termasuk seluruh aktivitas yang melibatkan fungsi manajemen secara keseluruhan yaitu kebijakan mutu, obyektifitas, tanggung jawab serta implementasi terhadap perencanaan, penjaminan, dan peningkatan (Susila, 2012). Manajemen kualitas dilakukan guna pihak yang terkait saat pelaksanaan konstruksi mampu mewujudkan hasil pekerjaan sesuai standar kualitas. Pelaksana manajemen kualitas tingkat paling bawah yaitu mandor, kriteria mandor yang mampu mengarahkan tenaga kerja (tukang) harus mengetahui keahlian/kualitas tukang dan pengalaman tukang (Gunasti, 2017). Pemilihan mandor untuk mengerjakan proyek konstruksi harusnya dengan memperhatikan kualitas yang dimiliki mandor tetapi yang terjadi kebanyakan di lapangan hanya sebatas rekomendasi dari proyek lain yang pernah menggunakan jasa mandor tanpa ada pemilihan secara kompetisi sesuai kemampuan dan keterampilan para mandor. Kontraktor kurang memperhatikan kemampuan dan kualifikasi mandor sehingga mengalami kesulitan dalam penentuan mandor yang memiliki pengetahuan dan berkualitas (Aryanto, 2013).

Kinerja mandor didefinisikan hasil yang dicapai dalam melaksanakan tugas yang dibebankan berdasarkan kecakapan, pengalaman, dan kesungguhan dalam batasan waktu (Mulyadi, 2014). Kinerja mandor dapat dinilai dari hasil kualitas pekerjaan yang telah diselesaikan dengan standar mutu perusahaan. Menurut Mushthofa tahun 2015, Kualitas pekerjaan tidak terlepas dari beberapa faktor yang mempengaruhi kinerja mandor, yaitu :

a. Pendidikan merupakan faktor yang mempengaruhi kinerja seorang mandor. Dasar pendidikan diperlukan untuk mengatasi permasalahan, maka dengan bantuan pelaksana atau Junior Engineering sebagai jembatan antara permasalahan dengan kesenjangan pendidikan mandor.

b. Pengalaman Kerja merupakan tingkat penguasaan serta keterampilan seseorang dalam pekerjaan yang dapat diukur dari masa kerja, pengetahuan dan keterampilan. Pengalaman mandor didapatkan berdasarkan siklus pekerjaan yang dimulai dari pekerja harian hingga menjadi wakil mandor.

c. Motivasi mandor, diartikan daya psikis yang mampu menggerakkan pekerja hingga menimbulkan kegiatan bekerja untuk mencapai tujuan. Motivasi yang dimiliki mandor dengan nilai jual hasil pekerjaannya (Fransisca, 2014). Faktor motivasi mandor antara lain upah, kondisi kerja, keamanan kerja, status, prosedur perusahaan, mutupenyediaan dan hubungan antar kolega kerja.

d. Disiplin Kerja dapat diartikan kemampuan mengatur diri, waktu, mengendalikan emosi, nafsu serta mengetahui cara menempatkan diri. Disiplin yang diterapkan mandor merupakan contoh bagi tenaga kerja agar menanamkan komitmen pada pekerjaan.

Menganalisis faktor pengaruh terhadap kemampuan mandor pada penerapan manajemen kualitas pada proyek apartemen Surabaya. Faktor yang mempengaruhi kemampuan mandor terdiri dari pendidikan, pengalaman kerja, motivasi, dan disiplin. Berdasarkan faktor tersebut maka dianalisis hubungan dan pengaruh terhadap kemampuan mandor dalam menerapkan manajemen kualitas pada proyek apartemen Surabaya.

\section{Metodologi Penelitian}

\subsection{Pengumpulan Data}

Metode Penelitian merupakan metode penentuan kebenaran dari sebuah pemikiran yang kritis (Anshori, 2017). Metode penelitian diikuti oleh pengumpulan data primer dan sekunder. Data primer merupakan data yang didapat langsung dari sumber aslinya, data primer berupa wawancara dan penyebaran kuesioner yang digunakan untuk mendapatkan karakteristik profil responden dan penilaian responden pada proyek pembangunan Apartmen Surabaya. 
Data sekunder berupa data standar mutu pekerjaan arsitek proyek pembangunan Apartmen Surabaya dan standar mutu yang didapatkan dari penelitian terdahulu. Berdasarkan data sekunder tersebut maka didapatkan output berupa variabel terikat (Y) yang digunakan sebagai standar acuan dalam penelitian.

\subsection{Populasi dan Teknik Sampling}

Populasi merupakan wilayah yang terdiri dari obyek dan subyek yang memiliki kuantitas dan karakteristik untuk mendapatkan tujuan tertentu, teknik pengambilan sampel menggunakan Probability Sampling yaitu teknik pengambilan sampel yang memberikan peluang yang sama bagi anggota populasi terpilih (Sugiyono, 2007). Populasi terdiri dari mandor hingga pekerja yang terdapat pada proyek ApartmenSurabaya. Total populasi \pm 120 orang, maka pengambilan sampel menggunakan Metode Slovin dengan hasil sebagai berikut :

$$
\mathrm{n}=\frac{120}{120 \cdot(0.05)^{2}+1}=92,3 \approx 95 \text { orang }
$$

\subsection{Tahapan Analisis/Penelitian}

Kuesioner yang telah disusun terlebih dahulu dilakukan pengujian Validitas dan Reliabilitas guna kelayakan dan konsistensi sebelum sebaran kuesioner. Penyebaran kuesioner dilakukan secara acak kepada mandor dan pekerja pada proyek Apartmen Surabaya dengan total 95 orang responden. Setelah didapat hasil dari penyebaran kuesioner, data diolah dengan dilakukan uji t dan uji F untuk mengetahui pengaruh variabel $\mathrm{X}$ dengan variabel $\mathrm{Y}$, dilanjutkan dengan uji asumsi klasik yang meliputi uji Multikolinearitas, uji Autokorelasi, uji Normalitas dan uji Homoskedastisitas.

Secara lengakap alur pada peneltian ini dapat dilihat pada gambar 1 berikut ini,

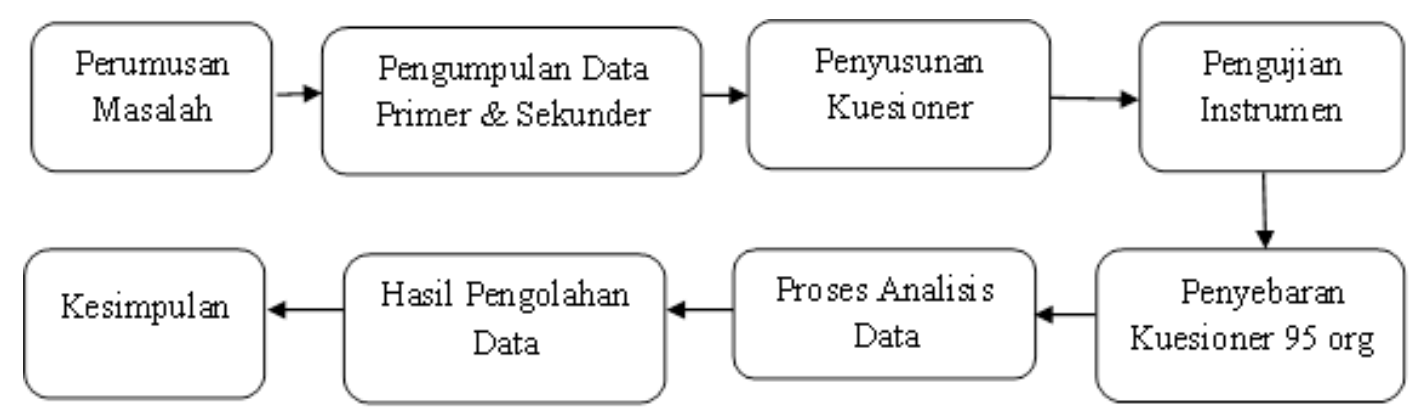

Gambar 1. Diagram alir penelitian

\section{Hasil Penelitian dan Pembahasan}

\subsection{Deskripsi Data}

Penyebaran kuesioner dengan sampel sebanyak 95 responden yaitu mandor dan para pekerja untuk pekerjaan arsitek. Komposisi dari responden yaitu jabatan mandor sebanyak 5 orang (5\%), kepala tukang sebanyak 11 orang $(11,5 \%)$, tukang sebanyak 45 orang $(47,4 \%)$ dan kuli atau pembantu tukang sebanyak 34 orang $(36,1 \%)$. Tingkat pendidikan SD terdapat 25 orang $(26,3 \%)$, tingkat SMP terdapat 51 orang $(53,7 \%)$ dan untuk tingkat SMA/ SMK terdapat 19 orang (20\%). Tingkat pengalaman kerja terdapat sebanyak 47 orang (49,5\%) untuk kerja 1-3 tahun, sebanyak 14 orang $(14,7 \%)$ untuk kerja selama 4-7 tahun, sebanyak 13 orang $(13,7 \%)$ untuk kerja selama 8-12 tahun, 
sebanyak 2 orang $(2,1 \%)$ untuk kerja selama $12-15$ tahun dan sebanyak 19 orang (20\%) untuk kerja lebih dari 15 tahun.

\subsection{Pengujian Instrumen}

Pengujian instrumen terdiri dari uji validitas dan uji reliabilitas. Uji validitas dilakukan untuk menguji ketepatan dan kecermatan instrumen (Ersi, 2010). Berdasarkan 21 item pertanyaan yang dilakukan uji validitas tersisa 18 item pertanyaan yang diujikan pada penelitian yang memiliki nilai valid lebih dari nilai $r$ tabel 0.202 dengan total 95 responden (>0.202). Setelah uji validitas lolos dilakukan pengujian selanjutnya yaitu uji reliabilitas.

Tabel 3.1. Tabel Hasil Uji Reliabilitas

\begin{tabular}{cccc}
\hline No & Variabel & Nilai Alpha Cronbacht & Keterangan \\
\hline 1 & Motivasi & 0.831 & Sangat Kuat \\
2 & Disiplin & 0.750 & Kuat \\
3 & M Kualitas & 0.762 & Kuat \\
\hline
\end{tabular}

Sumber : Hasil olahan data, 2019

Uji reliabilitas pada masing-masing variabel menghasilkan nilai sebesar 0,831 untuk variabel motivasi, 0,750 untuk variabel disiplin dan 0,762 untuk variabel manajemen kualitas. Sehingga variabel bebas dan terikat pada penelitian dikatakan memiliki nilai reliabilitas yang baik apabila nilainya diatas 0.60 untuk pengujian selanjutnya.

\subsection{Pengujian Analisis Data}

\subsubsection{Uji Multikolinearitas}

Pada Tabel 3.2. terlihat bahwa nilai VIF (Variance Inflation Factor) kurang dari $10(<10)$ sehingga dapat disimpulkan bahwa tidak terjadi multikolinearitas antara variabel bebas dengan variabel terikat penelitian yaitu korelasi antara variabel bebas dan variabel terikat tidak stabil dan cenderung berubah.

Tabel 3.2. Tabel Uji Multikolinearitas

\begin{tabular}{llccc}
\hline No & Variabel & Nilai VIF & Standart & Keterangan \\
\hline 1 & Pendidikan & 1.009 & $<10$ & Tdk Multikolinearitas \\
2 & Pengalaman & 1.164 & $<10$ & Tdk Multikolinearitas \\
3 & Motivasi & 1.361 & $<10$ & Tdk Multikolinearitas \\
4 & Disiplin & 1.260 & $<10$ & Tdk Multikolinearitas \\
\hline
\end{tabular}

Sumber : Hasil olahan data, 2019

\subsubsection{Uji Autokorelasi}

Tabel 3.3. Tabel Uji Durbin Watson

\begin{tabular}{llccl}
\hline No & dL & DW & dU & Keterangan \\
\hline 1 & 1.579 & 0.949 & 1.753 & Autokorelasi \\
\hline
\end{tabular}

Sumber : Hasil olahan data, 2019

Dilihat pada Tabel 3.3.bahwa nilai durbin watson sebesar 0,949 terletak kurang dari nilai 1,579 dL dan 1,753 dU sehingga terdapat gejala autokorelasi. Maka dilakukan perhitungan selanjutnya untuk mendeteksi autokorelasi dengan uji run test seperti pada Tabel 3.4 
Tabel 3.4. Tabel Uji Run Test

\begin{tabular}{llc}
\hline No & & Unstandardized Residual \\
\hline 1 & Test Value & 1.73599 \\
2 & Cases $<$ Test Value & 47 \\
3 & Cases $>$ Test Value & 48 \\
4 & Total Cases & 95 \\
5 & Number of Runs & 30 \\
6 & Z & -3.816 \\
7 & Asymp. Sig. (2-tailed) & 0.000 \\
\hline
\end{tabular}

Sumber : Hasil olahan data, 2019

Dari hasil pengujian Run Test didapatkan nilai signifikansi $0.000<0.05$. Maka dapat disimpulkan bahwa terdapat gejala autokorelasi pada penelitian.

\subsubsection{Uji Homoskedastisitas}

Tabel 3.5. Tabel Uji Homoskedastisitas

\begin{tabular}{llccc}
\hline No & Variabel & Nilai Sig & Standart & Keterangan \\
\hline 1 & Pendidikan & 0.119 & $>0.05$ & Homogen \\
2 & Pengalaman & 0.114 & $>0.05$ & Homogen \\
3 & Motivasi & 0.102 & $>0.05$ & Homogen \\
4 & Disiplin & 0.417 & $>0.05$ & Homogen \\
\hline
\end{tabular}

Sumber : Hasil olahan data, 2019

Pada Tabel 3.5. hasil pengujian didapat nilai signifikansi > standar keputusan $(0,05)$ jadi data dinyatakan baik memiliki varian yang sama (homogen).

3.3.4. Uji Normalitas

Tabel 3.6. Tabel Uji Kolmogorov Smirnov

\begin{tabular}{llc}
\hline No & & Unstandardized Residual \\
\hline 1 & $\mathrm{~N}$ & 92 \\
2 & Negative & -0.046 \\
3 & Test Statistic & 0.075 \\
4 & Asymp. Sig. (2-tailed) & 0.200 \\
\hline
\end{tabular}

Sumber : Hasil olahan data, 2019

Dari hasil pengujian didapatkan nilai asymp signifikansi $0.200>0.05$. Sehingga dapat disimpulkan bahwa model regresi berdistribusi normal.

\subsubsection{Uji t dan Uji F}

\begin{tabular}{llccc}
\multicolumn{2}{l}{ Tabel 3.7. Tabel Uji t } & & \\
\hline No & Variabel & t Hitung & t Tabel & Keterangan \\
\hline 1 & Pendidikan & 1.575 & 1.98 & Kurang Pengaruh \\
2 & Pengalaman & 2.520 & 1.98 & Berpengaruh \\
3 & Motivasi & 1.654 & 1.98 & Kurang Pengaruh \\
4 & Disiplin & -0.816 & 1.98 & Kurang Pengaruh \\
\hline \multicolumn{5}{l}{ Sumber : Hasil olahan data, 2019}
\end{tabular}

Tabel 3.7 merupakan hasil uji t yang menyatakan bahwa variabel bebas yaitu pendidikan, pengalaman kerja, motivasi dan disiplin diuji secara parsial terhadap kemampuan mandor dalam menerapkan manajemen kualitas, hasilnya untuk variabel pengalaman kerja berpengaruh terhadap kemampuan mandor dalam menerapkan manajemen kualitas sebesar 2,520 ( $\mathrm{t}$ hitung $>\mathrm{t}$ tabel). 
Sedangkan variabel pendidikan, motivasi dan disiplin kurang berpengaruh terhadap manajemen kualitas (t hitung < t tabel).

\begin{tabular}{llccc}
\multicolumn{6}{l}{ Tabel 3.8. Tabel Uji F } & & & \\
\hline No & Variabel & F Hitung & F Tabel & Keterangan \\
\hline 1 & Pendidikan & & & \\
2 & Pengalaman & 2.510 & 2.47 & Berpengaruh \\
3 & Motivasi & & & \\
4 & Disiplin & & & \\
\hline
\end{tabular}

Sumber : Hasil olahan data, 2019

Tabel 3.8 uji $\mathrm{F}$ yaitu pengujian secara simultan menyatakan bahwa seluruh variabel bebas berpengaruh terhadap kemampuan mandor dalam menerapkan manajemen kualitas sebesar 2,510 > 2,470 (F hitung > F tabel).

Tabel 3.9. Tabel Hubungan Variabel $X$ dan $Y$

\begin{tabular}{llccc}
\hline No & Model & $\mathbf{R}$ & $\boldsymbol{R}$ Square & Adjusted $\boldsymbol{R}$ Square \\
\hline 1 & 1 & 0.517 & 0.100 & 0.060 \\
\hline \multicolumn{2}{l}{ Sumber : Hasil olahan data, 2019} \\
\hline
\end{tabular}

Hubungan antara pendidikan, pengalaman kerja, motivasi dan disiplin mandor terhadap manajemen kualitas dengan nilai $\mathrm{R}$ sebesar 0,517. Hasil Uji secara parsial menghasilkan tidak semua variabel berpengaruh terhadap kemampuan mandor dalam menerapkan manajemen kualitas, seperti variabel pendidikan dengan nilai 1.575 kurang dari nilai t tabel 95 orang yaitu $1.98(1.575<1.98)$, variabel motivasi dengan nilai 1.654 kurang dari nilai t tabel 95 orang yaitu $1.98(1.654<1.98)$, variabel Pengalaman kerja dengan nilai 2.520 lebih dari nilai t tabel 95 orang yaitu $1.98(2.520>1.98)$ dan variabel disiplin dengan nilai 0.816 kurang dari nilai t tabel 95 orang yaitu $1.98(0.816<1.98)$. Hal ini didukung oleh penelitian Sukaratha, 2008 tentang "Analisis Kinerja Mandor Dalam Menerapkan Manajemen Kualitas Pada Proyek Pembangunan Nusa Dua Golf Resort Kawasan BTDC- Nusa Dua Bali" menyatakan bahwa hubungan antara pendidikan, pengalaman kerja, motivasi dan disiplin mandor dengan kemampuan mandor dalam menerapkan manajemen kualitas sangat rendah dan kurang signifikan. Tetapi pada pengujian secara simultan seluruh variabel berpengaruh terhadap kemampuan mandor dalam menerapkan manajemen kualitas juga didukung oleh penelitian Mushthofa, 2015 tentang "Analisa Pengaruh Kinerja Mandor Terhadap Kualitas Proyek Konstruksi di Kota Tuban" menyatakan bahwa pendidikan, pengalaman kerja, motivasi, disiplin mandor, kemampuan mandor dan hubungan organisasi dengan cukup pengaruh dengan nilai $\mathrm{R}$ sebesar 0,967 dalam menentukan kualitas proyek.

Dari Tabel 3.7 dan Tabel 3.8 yang menunjukkan bahwa variabel pendidikan, pengalaman kerja, motivasi dan disiplin secara simultan berpengaruh tetapi secara parsial tidak berpengaruh maka dilakukan pengujian lanjutan berupa uji t dan uji $\mathrm{F}$ untuk mengetahui karakteristik masing-masing variabel bebas terhadap variabel terikat.Berdasarkan perhitungan tersebut, diketahui hubungan pengaruh antar variabel serta didapatkan pola bahwa variabel yang berpasangan dengan pengalaman kerja memiliki hubungan pengaruh terhadap kemampuan mandor dalam menerapkan manajemen kualitas. Berdasarkan hasil pengujian tahap kedua, maka variabel yang tidak memiliki pengaruh terhadap kemampuan mandor dihilangkan sehingga mengerucut menjadi pengalaman kerja seperti terlihat pada Tabel 3.10. :

Tabel 3.10. Tabel Uji t

\begin{tabular}{|c|c|c|c|c|}
\hline No & Model & & $\mathrm{t}$ & Sig \\
\hline 1 & Constant & 36.130 & 14.279 & 0.000 \\
\hline 2 & $\mathrm{X} 2$ & 1.353 & 2.178 & 0.032 \\
\hline
\end{tabular}


Uji t pada Tabel 3.10 antara variabel pengalaman kerja dan kemampuan mandor dalam menerapkan manajemen kualitas proyek konstruksi didapatkan hasil sebesar 2,178 yang artinya berpengaruh, maka dapat dikategorikan variabel bebas penelitian yaitu variabel pengalaman kerja dengan variabel terikat berupa kemampuan mandor dalam menerapkan manajemen kualitas proyek konstruksi. Model regresi yang didapat dari hasil pengujian yang terdapat pada persamaan berikut :

$$
\mathrm{Y}=36,130+1,353 \mathrm{X} 2+\mathrm{ei}
$$

dimana,

$\mathrm{Y} \quad=$ variabel terikat (kemampuan mandor dalam menerapkan manajemen kualitas),

$\mathrm{X} 2$ = variabel bebas kedua (pengalaman kerja),

ei $=$ konstanta

Dari hasil persamaan didapatkan pola pengaruh variabel pengalaman kerja terhadap kemampuan mandor dalam menerapkan manajemen kualitas. Apabila variabel pengalaman kerja besarnya 0 maka kemampuan mandor dalam menerapkan manajemen kualitas besarnya sama dengan konstanta yaitu 36,130. Apabila variabel pengalaman kerja besarnya 1 maka kemampuan mandor dalam menerapkan manajemen kualitas besarnya sama dengan konstanta yaitu 37,483. Hal tersebut dapat diartikan bahwa apabila pihak manajemen memperhatikan pengalaman kerja maka kemampuan mandor dalam menerapkan manajemen kualitas akan meningkat.

\subsection{Hasil Pengolahan Data}

Hasil pengujian dari keempat variabel bebas yaitu pendidikan, pengalaman kerja, motivasi dan disiplin secara bersama-sama berpengaruh khususnya variabel pengalaman kerja berpengaruh terhadap variabel terikat. Pengujian yang dilakukan untuk menghasilkan bentuk regresi dari keseluruhan pengujian. Data hasil pengujian menjelaskan bahwa faktor pengalaman kerja mandor sangat berpengaruh pada kemampuan mandor dalam menerapkan manajemen kualitas. Faktor pendidikan, motivasi dan disiplin bukan berarti tidak berpengaruh sama sekali, tetapi pengaruhnya kecil bila dibandingkan dengan pengalaman kerja mandor. Hal tersebut terjadi pada proyek Apartmen Surabaya karena pengalaman kerja lebih dominan pengaruhnya terhadap kemampuan mandor dalam menerapkan manajemen kualitas. Hasil berbeda mungkin dapat dijumpai pada kasus/ proyek lainnya karena kebutuhan masing-masing proyek berbeda. Faktor pendidikan, motivasi dan disiplin mungkin pengaruhnya dapat ditingkatkan misalnya dengan memberikan pelatihan kerja khusus dan motivasi kepada mandor, pekerjanya dan dengan memberikan hadiah bagi yang tertib dalam melaksanakan instruksi serta memberlakukan denda bagi pelanggar peraturan yang disepakati.

\section{Kesimpulan}

Analisis pengujian penerapan manajemen kualitas terhadap pembangunan proyek apartmen mendapatkan hasil sebagai berikut :

1. Terdapat hubungan antara tingkat kemampuan mandor dalam menerapkan manajemen kualitas pada proyek Apartmen Surabaya dengan pendidikan, pengalaman kerja, motivasi dan disiplin dengan nilai $\mathrm{R}$ sebesar 0,517 .

2. Pengaruh kemampuan mandor dalam menerapkan manajemen kualitas pada proyek Apartment Surabaya cukup kuat dengan nilai sebesar 2,510 > 2,47. Pengalaman kerja berpengaruh terhadap Kemampuan mandor dalam menerapkan manajemen kualitas sebesar 2.178 ( Uji t).

\section{Daftar Pustaka}

Anshori, Muslich. 2017. Metodologi Penelitian Kuantitatif. Surabaya: Airlangga University Press. 
Aryanto, Dodi. 2013. Penilaian Kualifikasi Pengetahuan Mandor Konstruksi Berdasarkan SKKNI Pada Proyek Bangunan Gedung Di Wilayah Surabaya.

Ersi, Elisabet. 2010. Pengaruh Efektivitas Kepemimpinan Dukungan Organisasi Dan Program Pengembangan Karir Terhadap Kepuasan Kerja Karyawan RS. Stella Maris Makassar.

Fransisca. 2014. Pengaruh Motivasi Kerja Dan Kepuasan Kerja Terhadap Kinerja Karyawan. Jurnal Teknik Universitas Terbuka.

Gunasti, Amri. 2017. Penilaian Kinerja Tukang Dan Harapa n Mandor Dalam Proyek Konstruksi. Jember. Jurnal Penelitian Ipteks Januari 2017.

Mulyadi, Lalu. Dkk. 2014. Evakuasi Pengaruh Kinerja Mandor Terhadap Kualitas Pekerjaan Pembangunan Gedung Di Kabupaten Malang. Jurnal Info Manajemen Proyek, Vol. 5, 2014.

Mushthofa. 2015. Analisa Pengaruh Kinerja Mandor Terhadap Kualitas Proyek Konstruksi di Kota Tuban. Jurnal Teknik Sipil Untag Surabaya, Vol. 8 (2) : 149-162.

Sugiyono, Prof. Dr. 2007. Statistika Untuk Penelitian. Bandung: Alfabeta

Sukaratha, Gede. 2008. Analisis Kinerja Mandor Dalam Menerapkan Manajemen Kualitas Pada Proyek Pembangunan Nusa Dua Golf Resort Kawasan BTDC- Nusa Dua Bali. Jurnal Ilmiah Teknik Sipil, Vol. 12(1).

Susila, Herman. 2012. Penerapan Manajemen Mutu pada Proses Pembangunan Struktur Beton Gedung Rumah Susun Sederhana Sewa (Rusunawa) Surakarta. Jurnal Teknik Sipil Undip, 2012. 